\title{
Presynaptic Kainate Receptor Activation Preserves Asynchronous GABA Release Despite the Reduction in Synchronous Release from Hippocampal Cholecystokinin Interneurons
}

\author{
Michael I. Daw, ${ }^{1}$ Kenneth A. Pelkey, ${ }^{1}$ Ramesh Chittajallu, ${ }^{2}$ and Chris J. McBain ${ }^{1}$ \\ ${ }^{1}$ Program in Developmental Neuroscience, Eunice Kennedy Shriver National Institute of Child Health and Human Development, ${ }^{2}$ Developmental Synaptic \\ Plasticity Section, National Institute of Neurological Disorders and Stroke, National Institutes of Health, Bethesda, Maryland 20892
}

Inhibitory synaptic transmission in the hippocampus in mediated by a wide variety of different interneuron classes which are assumed to play different roles in network activity. Activation of presynaptic kainate receptors (KARs) has been shown to reduce inhibitory transmission but the interneuron class(es) at which they act is only recently beginning to emerge. Using paired recordings we show that KAR activation causes a decrease in presynaptic release from cholecystokinin (CCK)- but not parvalbumin-containing interneurons and that this decrease is observed when pyramidal cells, but not interneurons, are the postsynaptic target. We also show that although the synchronous release component is reduced, the barrage of asynchronous GABA release from CCK interneurons during sustained firing is unaffected by KAR activation. This indicates that presynaptic KARs preserve and act in concert with asynchronous release to switch CCK interneurons from a phasic inhibition mode to produce prolonged inhibition during periods of intense activity.

\section{Introduction}

Inhibitory synaptic transmission in the hippocampus is mediated by GABAergic interneurons consisting of multiple classes as defined by morphology, physiology and neurochemical markers (Klausberger and Somogyi, 2008). Interneuron classes are hypothesized to serve different roles in hippocampal network function. One factor which shapes these roles is the differential expression of presynaptic receptors to a variety of neurotransmitters, which modulate the release of GABA. For example parvalbumin (PV)-containing, fast-spiking basket cells (PV BCs) are influenced by relatively few types of receptors when compared with a second class of, cholecystokinin (CCK)-containing basket cells (CCK BCs). As such PV BCs are thought to represent immutable temporal enforcers while CCK BCs impose the influence of multiple hippocampal and nonhippocampal systems on to principal cells (Freund and Katona, 2007). Further emphasizing this divergence of function is the highly asynchronous release of GABA from CCK- but not PV-containing interneurons (Hefft and Jonas, 2005; Daw et al., 2009; Jonas and Hefft, 2010).

The presynaptic kainate (KA) class of glutamate receptors have been implicated in the modulation of synaptic release of both GABA

Received Dec. 21, 2009; revised May 31, 2010; accepted July 6, 2010.

This research was supported by the Intramural Research Program of the National Institute of Child Health and Human Development to C.J.M. Thanks to Josh Huang for the generous gift of the B13 PV-GFP mouse line and Gabor Szabó for the gift of the GAD-65 GFP line. We thank Christine Torborg for comments on the manuscript. We also thank Brian Jeffries for expert technical assistance.

Correspondence should be addressed to Michael I. Daw at his present address, Centre for Integrative Physiology, University of Edinburgh, Edinburgh, EH8 9XD, UK. E-mail: michael.daw@ed.ac.uk.

DOI:10.1523/JNEUROSCI.6334-09.2010

Copyright $\odot 2010$ the authors $\quad 0270-6474 / 10 / 3011202-08 \$ 15.00 / 0$ and glutamate in the hippocampus (Pinheiro and Mulle, 2008). Despite numerous studies there is no consensus on the effect of KA receptor (KAR) activation on GABA release. Application of glutamate, KA or the KAR agonist ATPA has been widely reported to increase the frequency of spontaneous IPSCs (sIPSCs) in pyramidal cells (Cossart et al., 1998; Frerking et al., 1999; Jiang et al., 2001; Semyanov and Kullmann, 2001; Fisahn et al., 2002; Maingret et al., 2005) but this is due, at least in part, to depolarization of interneurons (Cossart et al., 1998; Frerking et al., 1999; Jiang et al., 2001) or to increased axonal excitability (Semyanov and Kullmann, 2001; Maingret et al., 2005). While several studies have reported a reduction in the amplitude of evoked IPSCs (eIPSCs) on to pyramidal cells (Clarke et al., 1997; Rodríguez-Moreno et al., 1997; Behr et al., 2002; Maingret et al., 2005) this has been attributed to indirect effects (Frerking et al., 1999; Fisahn et al., 2002). This indirect interpretation has also been disputed (Rodríguez-Moreno et al., 2000; Maingret et al., 2005) and others have seen no reduction in eIPSCs (Cossart et al., 2001). Conversely KA is reported to increase eIPSCs in interneurons (Cossart et al., 2001). All of these studies on eIPSCs have relied on extracellular stimulation of local afferents meaning that the class of interneuron mediating the IPSC under study is unknown as is the interstimulus activity of these interneurons. Indeed, one study using paired interneuron to pyramidal cell recordings suggests that KA may increase GABA release from low release probability synapses a finding that may be due to spontaneous firing causing frequency-dependent facilitation (Jiang et al., 2001). A very recent study shows that KARs mediate the depression of evoked IPSC amplitude at synapses made by CCK interneurons via an enhancement of CB1 receptor-mediated depression (Lourenço et al., 2010). 
Here, using paired interneuron-pyramid and interneuroninterneuron recordings, we show that KAR activation causes a reduction in IPSC amplitude dependent on the identity of both presynaptic and postsynaptic cells. Furthermore we show that this reduction in IPSC amplitude from CCK interneurons is due to a decrease in synchronous GABA release without any effect on asynchronous release.

\section{Materials and Methods}

Slice preparation. Hippocampal slices $(300 \mu \mathrm{m}$ thick) were prepared from mice aged postnatal day 12 (P12)-P22. All animals were anesthetized with isoflurane before decapitation according to National Institutes of Health animal welfare guidelines. C57BL/6 mice or mice expressing GFP under the promoter for GAD-65 (Brager et al., 2003; Daw et al., 2009) or PV (B13 line) (Goldberg et al., 2008) were used as indicated. Brains were rapidly dissected out and placed in cold modified artificial CSF (aCSF) (see below) containing $0.5 \mathrm{mM} \mathrm{Ca}^{2+} / 4.5 \mathrm{mM} \mathrm{Mg}^{2+}$ or partial sucrose aCSF containing the following (in $\mathrm{mm}$ ): $80 \mathrm{NaCl}, 3.5 \mathrm{KCl}, 1.25$ $\mathrm{H}_{2} \mathrm{PO}_{4}, 25 \mathrm{NaHCO}_{3}, 4.5 \mathrm{MgSO}_{4}, 0.5 \mathrm{CaCl}_{2}, 10$ glucose, and 90 sucrose equilibrated with $95 \% \mathrm{O}_{2} / 5 \% \mathrm{CO}_{2}$. Brains were hemisected and transverse sections were cut with a Leica VT1000S microtome. Slices were incubated at $35^{\circ} \mathrm{C}$ for $30 \mathrm{~min}$ and at least a further $30 \mathrm{~min}$ at room temperature $\left(\sim 22^{\circ} \mathrm{C}\right)$ in the dissection solution before recording.

Whole-cell recordings. Slices were transferred to a recording chamber and perfused with aCSF containing $125 \mathrm{~mm} \mathrm{NaCl}, 3.5 \mathrm{~mm} \mathrm{KCl}, 1.25 \mathrm{~mm}$ $\mathrm{H}_{2} \mathrm{PO}_{4}, 25 \mathrm{~mm} \mathrm{NaHCO}_{3}, 1.5 \mathrm{~mm} \mathrm{MgSO}_{4}, 2.5 \mathrm{~mm} \mathrm{CaCl}_{2}$ (or as indicated) and $20 \mathrm{~mm}$ glucose, equilibrated with $95 \% \mathrm{O}_{2} / 5 \% \mathrm{CO}_{2}$ and maintained at $33-35^{\circ} \mathrm{C}$. Cells were visualized using a $40 \times$ objective and IR-DIC video microscopy (Zeiss Axioskop 2 FS Plus). Fluorescence of GFP-containing cells was excited by a Lamda LS light source (Sutter Instruments) and visualized online using Spot Basic imaging software and RT KE camera (both Diagnostic Instruments Inc). Whole-cell recordings were made using a Multiclamp 700A amplifier (Molecular Devices). Recording electrodes (3-5 M $\Omega$ ) were filled with a solution containing $130 \mathrm{~mm} \mathrm{KCl,} 8.5$ mm NaCl, 4 mm MgATP, $0.3 \mathrm{~mm} \mathrm{Na}$ GTP, 5 mm HEPES and $0.5 \mathrm{~mm}$ EGTA adjusted to $\mathrm{pH} 7.3$ using $\mathrm{KOH}$ and $290 \mathrm{mOsm}$ using sucrose. Biocytin $(2 \mathrm{mg} / \mathrm{ml})$ was added on the day of recording. Uncompensated series resistance (8-25 $\mathrm{M} \Omega$ for interneurons, 5-20 $\mathrm{M} \Omega$ for pyramidal cells/granule cells) was monitored in postsynaptic cells via a $-5 \mathrm{mV}$ voltage step and recordings stopped after changes $>30 \%$. Firing patterns were investigated by giving a series of incrementing $500 \mathrm{~ms}$ duration current steps from $-70 \mathrm{mV}$ of between 20 and $150 \mathrm{pA}$ step sizes starting from a negative step of double the step amplitude until at least double action potential threshold amplitude. During drug application synaptic transmission was monitored by producing pairs of action potentials in the presynaptic cell at $50 \mathrm{~Hz}$ every $10 \mathrm{~s}$ by giving $2 \mathrm{~ms} 1-2 \mathrm{nA}$ current steps. Presynaptic trains before and after drug application consisted of 25 presynaptic action potentials at $50 \mathrm{~Hz}$ from $-70 \mathrm{mV}$ while holding the postsynaptic cell at $-70 \mathrm{mV}$ in voltage clamp. Ten trains were delivered at $0.1 \mathrm{~Hz}$. Trains were not delivered during KA application as postsynaptic responses to trains were often not stable if delivered over a prolonged period of time. Data were acquired at $10 \mathrm{kHz}$ using Pclamp 9.2 (Molecular Devices) and filtered at $4 \mathrm{kHz}$.

Data analysis. Points in amplitude vs time plots represent the peak amplitude derived from an average of 6 consecutive traces. Values stated in text are the peak amplitude derived from an average of 24 traces either immediately before or 6-10 min after drug application. Averaging was performed to increase the signal-to-noise ratio particularly for small amplitude IPSCs. Success rate is 1- failure rate; we used this parameter to allow calculation of percentage change when baseline failure rate $=0$.

To determine synchronous and asynchronous GABA release, trains were deconvolved as follows using IgorPro (Wavemetrics). An artificial mIPSC was created using the rise to peak of a recorded unitary IPSC and a single exponential decay to baseline calculated from a fit of the IPSC to remove noise. Separate artificial mIPSCs were created for each pair analyzed based on the kinetics of the IPSCs recorded in that pair. This mIPSC was then scaled to give a peak of $20 \mathrm{pA}$. This value was chosen as close to the smallest events detected after the train in most cells. Baseline was subtracted from postsynaptic waveforms and 20 repetitions of binomial (Gaussian) smoothing were applied. Fourier transforms of the mIPSC and individual trains were calculated. The Fourier transform of the mIPSC was then divided, point by point, in to the Fourier transform of the train. The quotient of this division was returned to the time domain via the inverse Fourier transform to produce the release rate histogram (Diamond and Jahr, 1995). Synchronous release was calculated from the area under the release rate histogram for the $5 \mathrm{~ms}$ following the onset of the presynaptic current step while asynchronous release was the area of the following $15 \mathrm{~ms}$ (see Fig. 5A, inset) and, when calculating asynchronous release for the entire burst, for the period following the last step until the end of the trace. Asynchronous release after the end of the train was included only for data referring to the entire train. This method almost certainly underestimates the degree of asynchronous release (e.g., one third of truly random release would be regarded as synchronous) but does so equally across all cells and allows for jitter in spike timing and in the delay to the onset of the synchronous IPSC. Both modes of release were calculated from an average of 10 release rate histograms each calculated from a single postsynaptic waveform. Synchronicity ratio (SR) was simply synchronous release/asynchronous release from the start of the train to the end of the sweep (Daw et al., 2009).

All values of statistical significance are results of two-tailed $t$ tests, a value of $<0.05$ was considered significant. All statistics are shown \pm SEM and illustrated in graphs as mean value with error bars representing SEM.

Anatomical reconstruction. After biocytin filling during whole-cell recordings, slices were fixed with $4 \%$ paraformaldehyde and stored at $4{ }^{\circ} \mathrm{C}$ then permeabilized with $0.3 \%$ Triton X-100 and incubated with Alexa Fluor 555 or Alexa Fluor 633-conjugate streptavidin. Resectioned slices were mounted on gelatin-coated slides using Mowiol mounting medium. Cells were visualized using epifluorescence microscopy (Olympus AX70) and images for representative examples were obtained with a Leica TCS SP2 RS Confocal Microscope. Frames of maximum projection images were created from stacks ( $2 \mu \mathrm{m}$ steps $)$ and stitched together in Adobe Photoshop.

\section{Results}

We investigated whether the effect of KAR activation on inhibitory synaptic transmission in the hippocampus depends on the identity of presynaptic and postsynaptic cells by making wholecell recordings from synaptically connected interneuroninterneuron or interneuron-pyramidal cell/granule cell pairs in the CA1, CA3 and dentate gyrus regions of the hippocampus [collectively referred to as principal cells (PCs)]. CCK interneuron recordings were made from GFP-positive cells in a mouse line expressing EGFP under a GAD-65 promoter (Brager et al., 2003). We have previously characterized GFP-positive cells recorded from the pyramidal layer and inner third of stratum radiatum in this mouse line (Daw et al., 2009). We found that cells which produced a barrage of asynchronous IPSCs in response to long trains of action potentials also displayed depolarizationinduced suppression of inhibition, which is specific to CCK interneurons (Katona et al., 1999; Wilson et al., 2001; Földy et al., 2007), and were positive for CCK mRNA when tested with single cell rtPCR. Two other groups have previously shown this highly asynchronous GABA release to be a phenomenon specific to CCK interneurons of both the dentate and CA regions of the hippocampus (Hefft and Jonas, 2005; Karson et al., 2009). We used deconvolution analysis (see methods) to determine the SR during trains of 25 action potentials at $50 \mathrm{~Hz}$ for each neuron pair calculated as total synchronous GABA release/total asynchronous release. We included only those synaptic connections which displayed an SR $<3$ (Daw et al., 2009) in the CCK-interneuron set. Morphology of interneurons demonstrating asynchronous release was recovered for 42/52 presynaptic cells and were consistent with the CCK-positive cell classes we reported in our previous study (Daw et al., 2009) (supplemental Figs. S1-S3, 

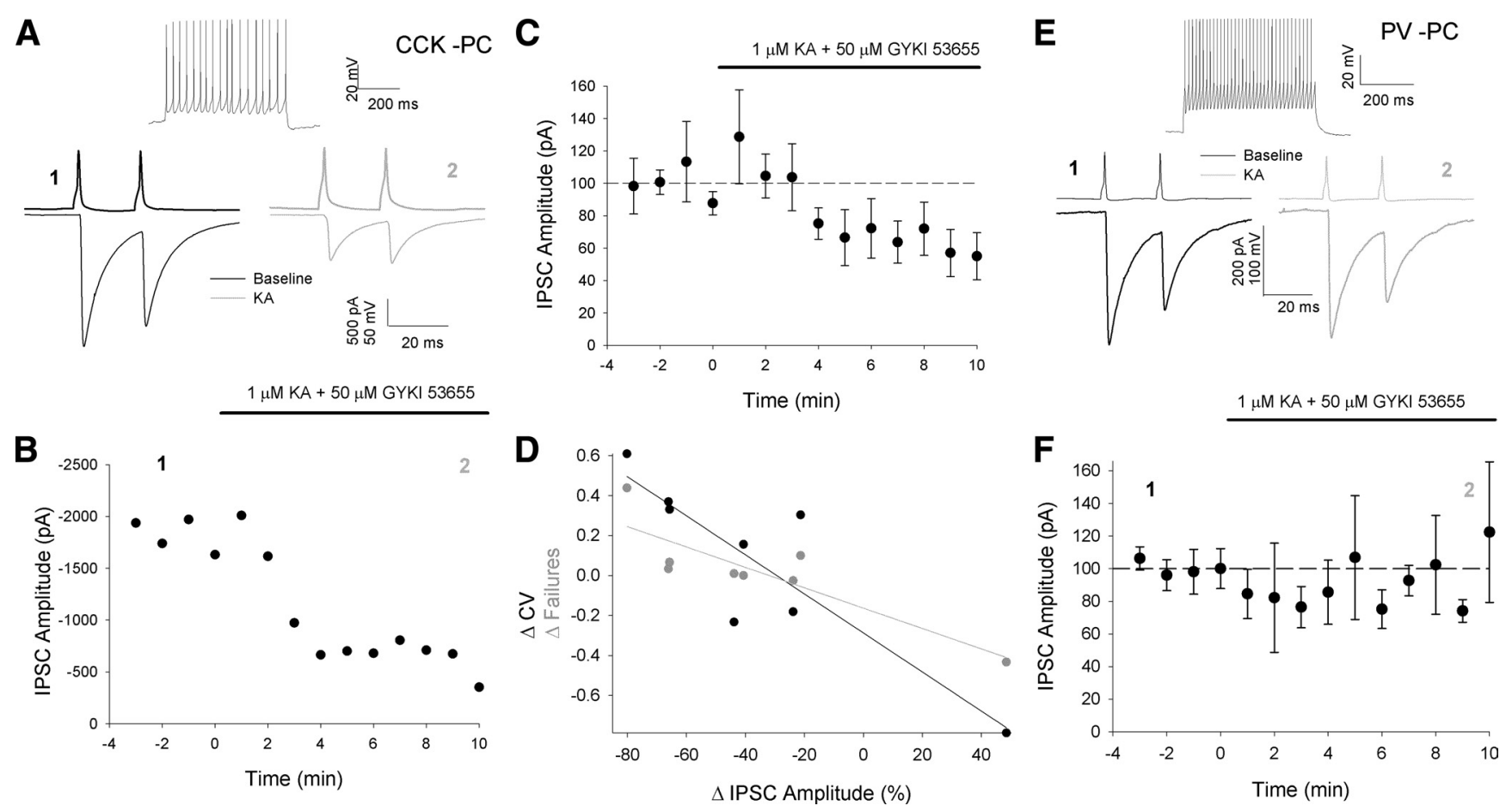

Figure 1. Presynaptic KAR activation decreases IPSC amplitude in PCs when CCK but not PV interneurons are presynaptic. $A$, Example CCK interneuron to $P C$ pair. Top shows presynaptic cell response to $500 \mathrm{~ms}$ current step at double threshold amplitude (160 pA). Bottom shows an average of 24 paired pulse traces before (left, black) and after (right, gray) $1 \mu \mathrm{m} \mathrm{KA} \mathrm{application} \mathrm{taken} \mathrm{at}$ time points indicated in $\boldsymbol{B}$. Top trace, presynaptic cell; bottom trace, postsynaptic cell. This applies to all paired pulse traces in this and later figures. $\boldsymbol{B}$, Peak first IPSC amplitude vs time plot for example shown in $\boldsymbol{A}$. Each point represents the peak amplitude of an average of 6 traces. This applies to all amplitude vs time plots in this and later figures. $\boldsymbol{C}$, Average data for all experiments as shown in $\boldsymbol{A}$ and $\boldsymbol{B}, n=8$. D, Plot of change in IPSC amplitude after $1 \mu \mathrm{m} \mathrm{KA}$ application vs change in CV (black) and failures (gray) $\boldsymbol{E}$, Example PV interneuron to $\mathrm{PC}$ pair. Top shows presynaptic cell response to $500 \mathrm{~ms}$ current step at double threshold amplitude (1200 pA). F, Amplitude vs time plot for all PV interneuron to PC pairs, $n=6$. For this and subsequent figures cell types in pairs are labeled as follows: CCK, CCK intereneuron; PV, PV interneuron; PC, principal cell (pyramidal/granule).

available at www.jneurosci.org as supplemental material). Interneurons which were postsynaptic to CCK interneurons were also GAD-65 GFP positive and had firing patterns and, when recovered (7/17), morphologies which were consistent with CCK interneurons although this was not confirmed (supplemental Fig. S4, available at www.jneurosci.org as supplemental material).

Presumed PV-containing interneurons were identified using a mouse line expressing EGFP under a PV promoter (B13 line) (Goldberg et al., 2008) or by their firing properties in wild-type mice or non-GFP-positive cells in GAD65-GFP mice using criteria we have established previously (Daw et al., 2009). PVcontaining interneurons were typified by a fast-spiking (FS) phenotype comprising narrow action potentials with deep, brief afterhyperpolarization (AHP) and a lack of spike frequency adaptation (Fig. 1E) (Kawaguchi et al., 1987). Interneurons that were postsynaptic to PV interneurons were also PV interneurons as determined by FS phenotype.

\section{IPSCs on to pyramidal cells mediated by CCK- but not PV-containing interneurons are inhibited by KA}

IPSC amplitude was monitored in postsynaptic PCs held in voltage clamp at $-70 \mathrm{mV}\left(\mathrm{GABA}_{\mathrm{A}}\right.$-mediated IPSC is an inward current due to symmetrical $\mathrm{Cl}^{-}$concentration) while pairs of action potentials were evoked at $50 \mathrm{~Hz}$ in the presynaptic cells by depolarizing current steps every $10 \mathrm{~s}$. After a 4 min baseline period 1 $\mu \mathrm{M}$ KA was bath applied together with $50 \mu \mathrm{M}$ GYKI 53655 to prevent activation of AMPA receptors. When CCK interneurons were presynaptic, IPSC amplitude was significantly reduced by 1 $\mu \mathrm{M}$ KA (IPSC amplitude 6-10 min after $1 \mu \mathrm{M} \mathrm{KA}$ application $=$ $63 \pm 15 \%$ baseline, $p<0.05, n=8$, Figs. $1 A-C, 2 C)$. Coefficient of variation $(\mathrm{CV})$ and failure analysis demonstrate that this reduction is due to a decrease in presynaptic release as the change in IPSC amplitude is strongly negatively correlated with changes in both parameters $\left(\mathrm{CV}: R^{2}=0.77, p\right.$ for slope fit $=0.005$, failures: $R^{2}=0.75, p$ for slope fit $=0.01$, Fig. $\left.1 D\right)$. The reduction in IPSC amplitude produced by $1 \mu \mathrm{M} \mathrm{KA}$ is a specific result of KAR activation as no effect was seen when $1 \mu \mathrm{M}$ KA was applied together with both the AMPA-selective antagonist GYKI 53655 and the AMPA/KA antagonist CNQX ( $50 \mu \mathrm{M}$, IPSC $=103 \pm 26 \%$ baseline, $p=0.86, n=6$, Fig. $2 C$ ). In contrast when PV interneurons were presynaptic KA had no effect on IPSC amplitude (IPSC = $101 \pm 25 \%$ baseline, $p=0.97, n=6$, Fig. $1 E, F), C V(124 \pm 20 \%$ baseline, $n=6, p=0.3$ ) or success rate (101 $\pm 1 \%$ baseline, $n=$ $6, p=0.2)$.

\section{Kainate depresses IPSCs at low concentration at GluK1 receptors}

At CA3 mossy fibers application of KA in the low micromolar range results in a depression of EPSCs, but conversely, lower concentrations cause an increase in EPSC amplitude (Schmitz et al., 2001). To test whether this bimodal effect of KA also exists at CCK interneuron synapses we applied $200 \mathrm{~nm}$ KA during recordings of CCK interneuron to PC pairs. Additionally to separate the effect of KAR activation from that of AMPA receptor inhibition we applied KA after prior application of GYKI 53655. In contrast to mossy fiber synapses this low concentration of KA resulted in a depression of CCK interneuron-mediated IPSCs indistinguishable to that caused by $1 \mu \mathrm{M} \mathrm{KA}$ (IPSC $=59 \pm 5 \%$ baseline, $p$ vs baseline $<0.05$, $p$ vs $1 \mu \mathrm{M} \mathrm{KA}=0.8, n=7$ ) (Fig. $2 A, C$; supplemental Fig. S1, available at www.jneurosci.org as supplemental 
A
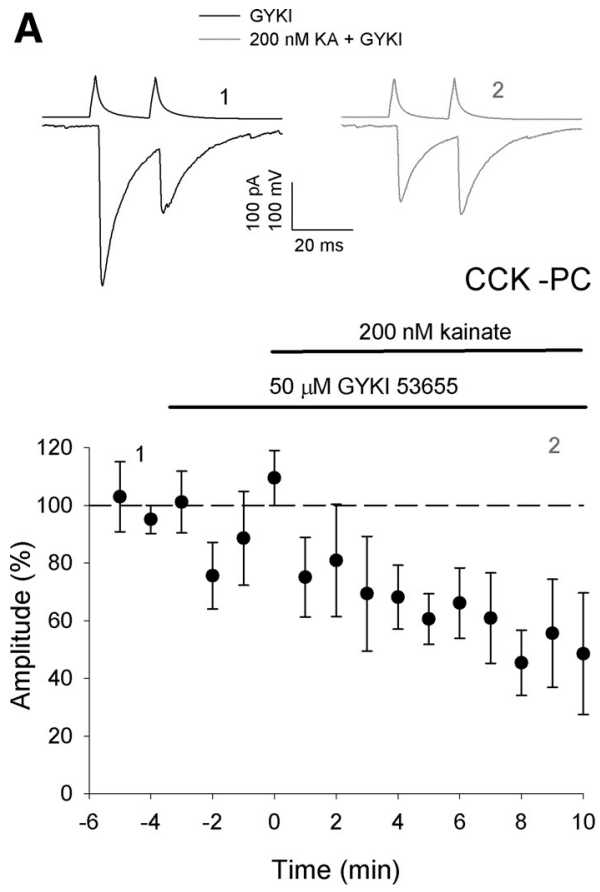

B

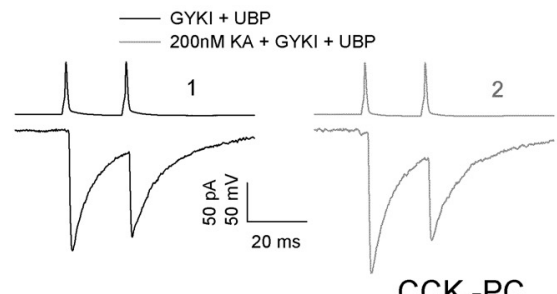

CCK -PC

$200 \mathrm{nM}$ kainate

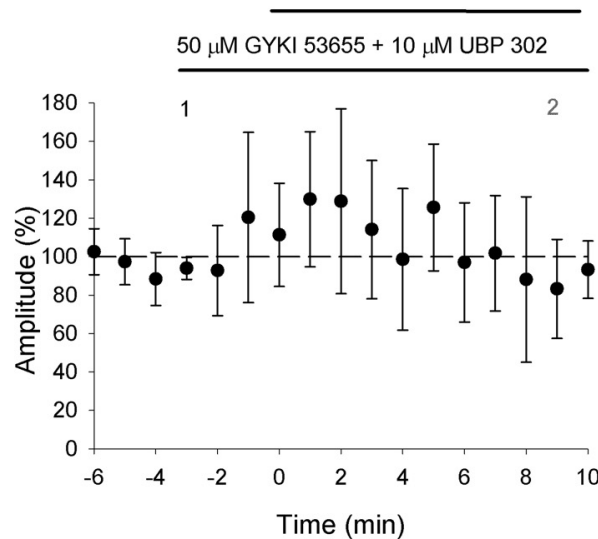

C

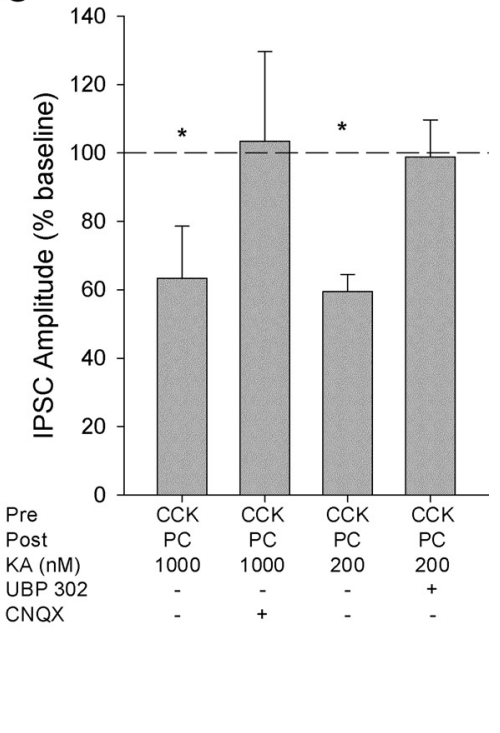

Figure 2. KA acts at nanomolar concentration at GluK1 receptors. $A$, Traces and amplitude vs time plot showing effect of $200 \mathrm{~nm}$ KA application at CCK interneuron to $\mathrm{PC}$ synapses after prior application of 50 $\mu \mathrm{m} \mathrm{GYKI} 53655 n=7 . \boldsymbol{B}$, Traces and amplitude vs time plot showing effect of $200 \mathrm{~nm}$ KA application at CCKinterneuron to PC synapses after prior application of $50 \mu \mathrm{m} \mathrm{GYKI} 53655$ and $2 \mu \mathrm{m}$ UBP302 $n=6 . C$, Bar graph showing ulPSC amplitude as percentage baseline after application of the drugs shown: CCK to PC $1 \mu \mathrm{m} \mathrm{KA,} n=8$; CCK to PC $1 \mu \mathrm{m} \mathrm{KA}+$ CNQX, $n=6 .{ }^{*} p<0.05$ vs baseline.

material). In a number of systems presynaptic actions of KAR activation have been ascribed to GluK1(formerly GluR5)-containing receptors (Clarke et al., 1997; Vignes et al., 1998; Fisahn et al., 2002; Lourenço et al., 2010). To test
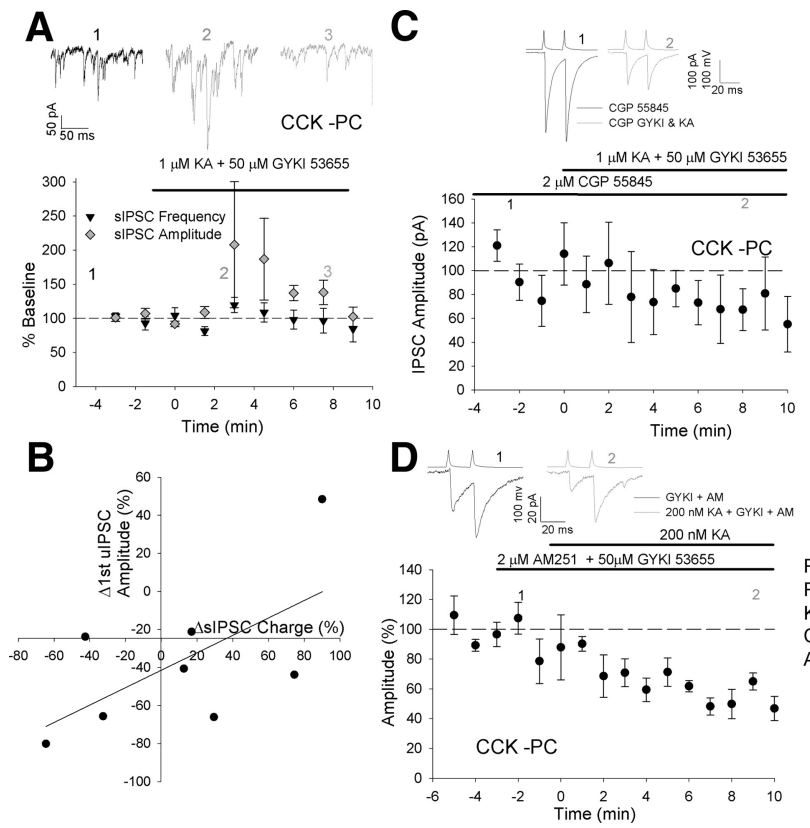

E

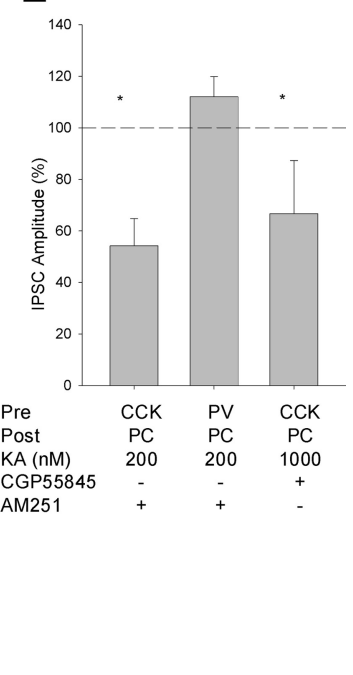

Figure 3. Reduction in IPSC amplitude is not due to indirect effects of an increase in sIPSCS or $G A B A_{B}$ or CB1 receptor activation. $A$, Time plot for average sIPSC frequency (black triangles) and amplitude (gray diamonds) for all CCK interneuron to $\mathrm{PC}$ pairs during $1 \mu \mathrm{M}$ KA application, $n=6$. Traces showing sIPSCs in a PC from an example experiment at the time points indicated before (black) and $3 \mathrm{~min}$ (dark gray) and $10 \mathrm{~min}$ (light gray) after $1 \mu \mathrm{m} \mathrm{KA}$ application. $\boldsymbol{B}$, Change in first evoked IPSC amplitude vs the change in sIPSC charge (frequency $\times$ amplitude) after KA application in CCK interneuron to pyramidal cell pairs. C, Time plot and traces showing effect of $1 \mu \mathrm{M}$ KA application at CCK interneuron to PC synapses in the presence of the GABA ${ }_{B}$ antagonist $2 \mu \mathrm{M}$ CGP 55845; $n=7$. D. Time plot and traces showing effect of $200 \mathrm{~nm}$ KA application at CCK interneuron to $\mathrm{PC}$ synapses after prior application of $2 \mu \mathrm{M} \mathrm{AM} 251$ and $50 \mu \mathrm{M} \mathrm{GYKI53655;} n=6$.E, Bar graph showing ulPSC amplitude as percentage baseline after application of the drugs shown. $\mathrm{PV}$ to $\mathrm{PC} 200$ nм KA $+\mathrm{AM} 251, n=4 .{ }^{*} p<0.05$ vs baseline. whether this subtype was also responsible for the inhibition of CCK interneuronmediated IPSCs we applied $200 \mathrm{~nm}$ KA in the presence of GYKI 53655 and the specific GluK1 antagonist UBP302 (10 $\mu \mathrm{M})$. Inhibition of GluK1 abolished the depression of IPSC amplitude showing that KA acts via GluK1-containing receptors IPSC $=99 \pm 11 \%$ baseline, $p=0.4, p$ vs $200 \mathrm{nM}$ KA alone $<0.01, n=7$ ) (Fig. $2 B, C$; supplemental Fig. S2, available at www.jneurosci.org as supplemental material).

Reduction in IPSC amplitude is not via an indirect activation of $\mathrm{GABA}_{\mathrm{B}}$ or CB1 receptors

The reduction in evoked IPSC amplitude in hippocampal pyramidal cells caused by KAR activation has been attributed to an indirect result of the increase in sIPSCs due to both activation of presynaptic $\mathrm{GABA}_{\mathrm{B}}$ receptors and to a reduction in postsynaptic input resistance (Frerking et al., 1999; Fisahn et al., 2002). Consistent with previous reports in the presence of KA we observed an increase in sIPSC frequency in PCs. However this increase was transient and had returned to baseline frequency 6-10 min following $1 \mu \mathrm{M} \mathrm{KA}$ application, at which time the reduction in 
unitary IPSC (UIPSC) amplitude was measured (sIPSC frequency 6-10 min after $1 \mu \mathrm{M}$ KA application $=126 \pm 13 \%$ baseline, $p=0.3, n=8$, Fig. $3 A$ ). sIPSC amplitude was also unchanged (sIPSC amplitude $=96 \pm 1 \%$ baseline, $p=0.8$, $n=8$, Fig. $3 A$ ) in the presence of $1 \mu \mathrm{M} \mathrm{KA}$. If the uIPSC reduction caused by $1 \mu \mathrm{M} \mathrm{KA}$ were indirectly produced by an increase in sIPSCs a negative correlation would be expected between the change in UIPSC amplitude and the change in sIPSC charge (frequency $X$ amplitude). Such a negative correlation does not exist in our data (linear regression slope $=0.46, R^{2}=0.39, p$ for slope fit $=0.1$, Fig. $3 B$ ). A crucial factor in our experiments is that we were able to prevent spontaneous firing of presynaptic interneurons which may increase upon kainate application (Frerking et al., 1999; Fisahn et al., 2002) by delivering tonic hyperpolarizing current. This prevents frequency-dependent, short-term plasticity from masking direct changes in release probability. Furthermore KA did not cause a reduction in postsynaptic input resistance (input resistance baseline $=$ $98 \pm 11 \mathrm{M} \Omega, 6-10 \mathrm{~min}$ after $1 \mu \mathrm{M} \mathrm{KA}$ application $=123 \pm 27 \mathrm{M} \Omega, n=8, p=$ 0.2 ). Finally after preapplying the $G_{A B} A_{B}$ receptor antagonist CGP $55845(2 \mu \mathrm{M}) 1$ $\mu \mathrm{M}$ KA application caused a very similar reduction in uIPSC amplitude (IPSC amplitude in $1 \mu \mathrm{M} \mathrm{KA}$, GYKI and CGP = $67 \pm 21 \%$ uIPSC in CGP alone, $p<0.05$, $n=7, p=0.9$ vs KA alone, Fig. $3 C, E)$. These data confirm that the effects of kainate application are likely due to direct activation of presynaptic KARs on CCK interneurons.

A recent study has described a mechanism by which KAR activation reduces CCK interneuron-mediated IPSCs by facilitating the effect of $\mathrm{CB} 1$ receptor activation such that when $\mathrm{CB1}$ receptors are blocked pharmacologically KAR activation no longer reduces IPSC amplitude (Lourenço et al., 2010). As part of this mechanism $\mathrm{CB} 1$ receptor activation requires $\mathrm{mGluR}$-mediated release of the endogenous CB1 agonist 2-AG. In our study it is unclear how mGluRs would be activated but it is possible that CB1 receptors are tonically activated so we tested whether the inhibitory effect of $200 \mathrm{~nm} \mathrm{KA}$ was due to facilitation of the effect of CB1 receptor signaling by applying $\mathrm{KA}$ in the presence of the $\mathrm{CB} 1$ antagonist AM251. With CB1 receptors blocked KA still induced a reduction in IPSC amplitude in CCK interneuron-PC pairs (IPSC amplitude in $200 \mathrm{~nm} \mathrm{KA}, \mathrm{AM} 251$ and GYKI $=54 \pm 11 \%$ uIPSC in AM251 and GYKI alone, $p<0.05, n=6, p=0.6$ vs 200 nм KA alone, Fig. $3 D, E$; supplemental Fig. S3, available at www. jneurosci.org as supplemental material). As expected prior application of the CB1 antagonist also did not reveal an effect of KA at PV interneuron to PC synapses (IPSC amplitude in $200 \mathrm{nM} \mathrm{KA}$, AM251 and GYKI $=112 \pm 8 \%$ uIPSC in AM251 and GYKI alone, $p<0.05, n=4$, Fig. $3 E)$. indicated.
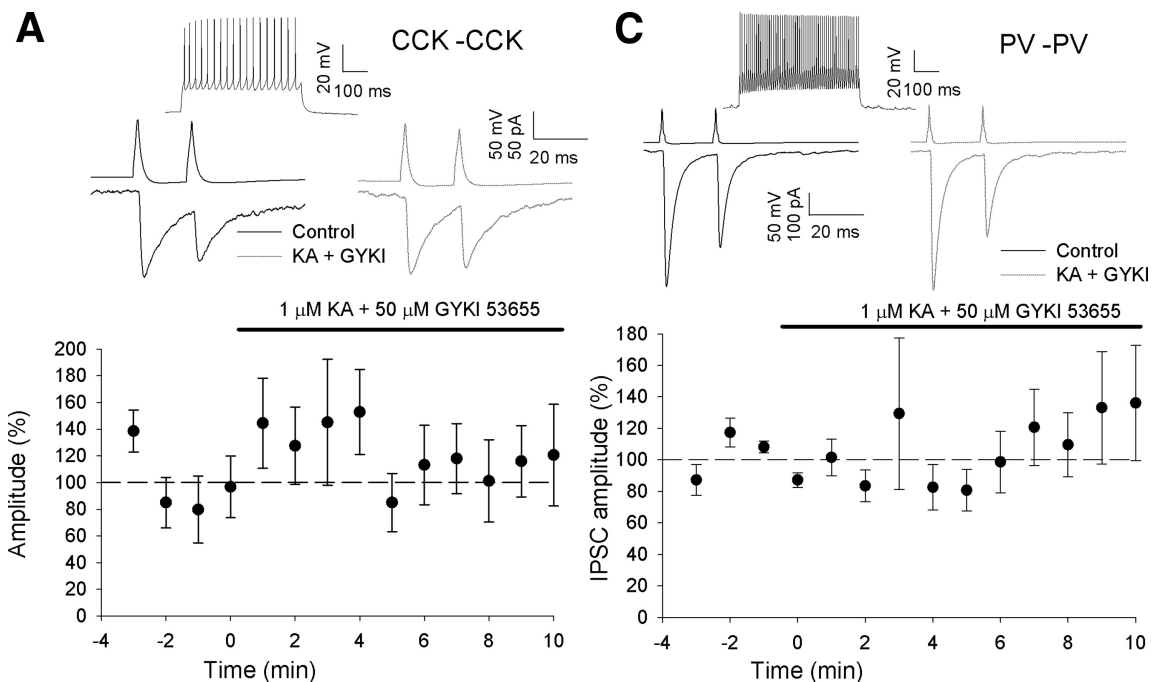

$1 \mu \mathrm{M}$ KA $+50 \mu \mathrm{M}$ GYKI 53655
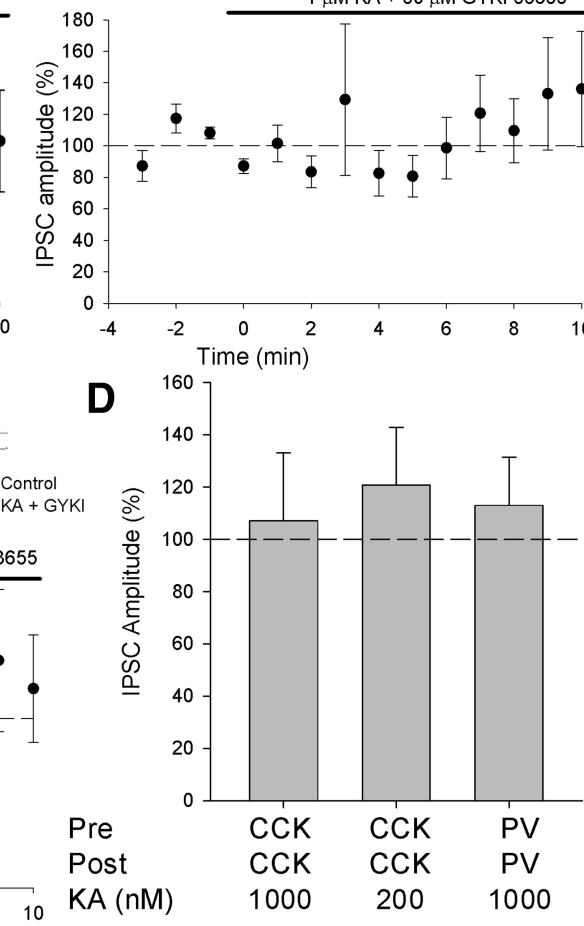

Time (min)

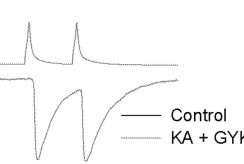

$200 \mathrm{nM} \mathrm{KA}+50 \mu \mathrm{M}$ GYKI 53655 作 列 amplitude $(800 \mathrm{pA})$. D, Bar chart showing effect of KA application at interneuron to interneuron synapses in the conditions

\section{Absence of KA-induced depression at CCK interneuron- interneuron synapses}

KAR activation has been reported to have different effects on IPSCs on to pyramidal cells and interneurons in the hippocampus (Cossart et al., 2001). We examined this by making paired interneuron-interneuron recordings. KA application had no effect on the amplitude of IPSCs in interneurons at synapses made by either PV interneurons (IPSC $113 \pm 18 \%$ baseline, $n=7, p=$ 0.5 , Fig. $4 C, D$ ) or CCK interneurons (IPSC $107 \pm 26 \%$ baseline, $n=13, p=0.8$, Fig. $4 A, D)$. As for IN-PC synapses there is no correlation between the change in sIPSC charge and uIPSC amplitude (linear regression slope $=0.43, R^{2}=0.08, p$ slope fit $=$ 0.4 , data not shown) suggesting that activation of $\mathrm{GABA}_{\mathrm{B}}$ receptors as a result of spontaneously released GABA is unlikely to affect the observed UIPSC amplitude. Although we have shown that KA causes a reduction in IPSC amplitude onto PCs at both high and low concentrations it is possible that $1 \mu \mathrm{M}$ lies in the middle of a bimodal effect of KA at CCK interneuron to interneuron synapses. To test this we applied $200 \mathrm{~nm}$ kainate to CCK interneuron pairs. As for $1 \mu \mathrm{M}, 200 \mathrm{~nm}$ had no effect on uIPSC amplitude (IPSC $126 \pm 26 \%$ baseline, $n=3, p=0.4$, 

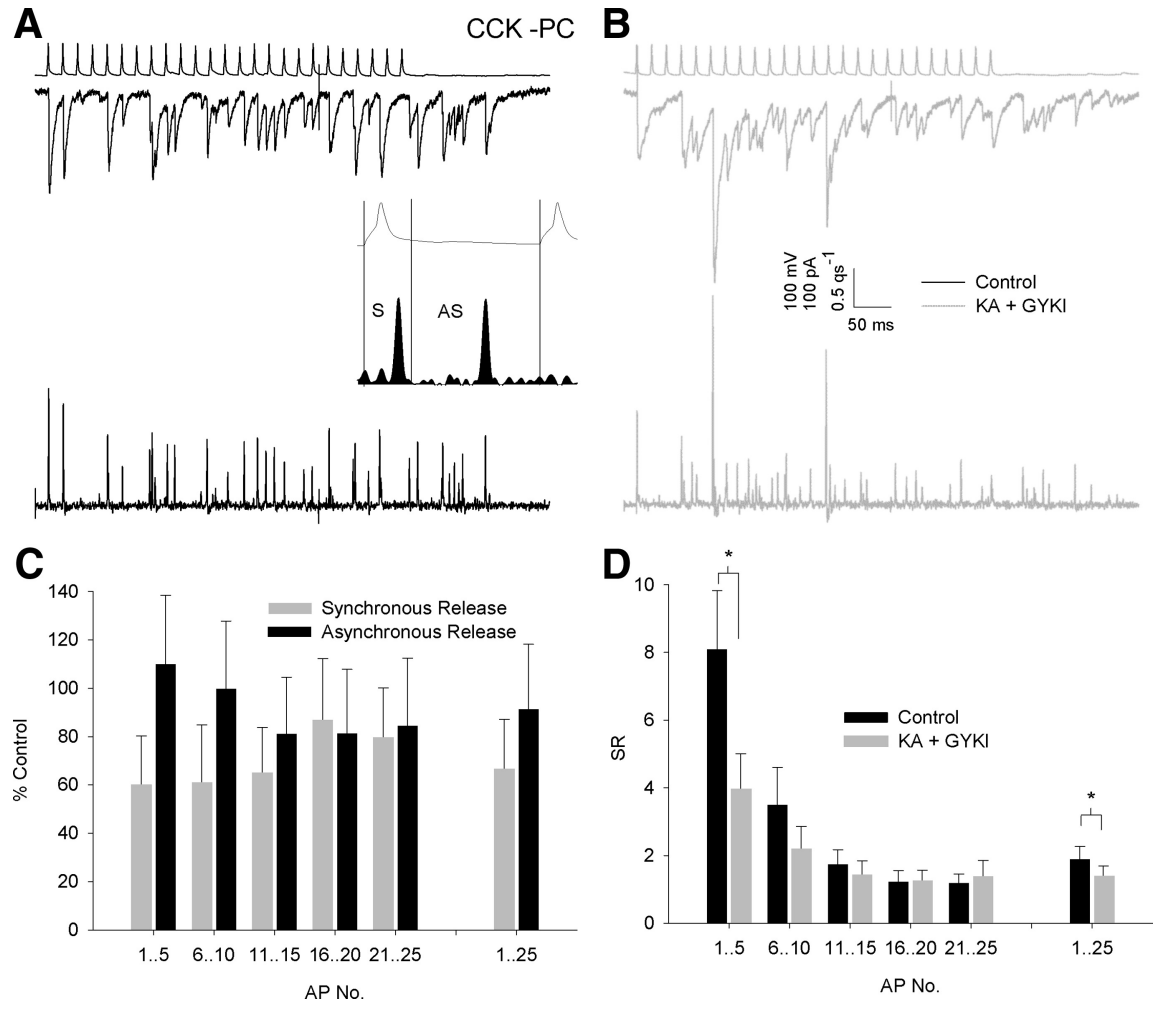

Figure 5. Reduction in IPSC amplitude is specific to synchronous release. A, Example CCK interneuron to pyramidal cell pair before $1 \mu \mathrm{m}$ KA application. Top trace shows presynaptic action potentials. Middle trace shows postsynaptic voltage-clamp response. Bottom trace shows release rate histogram deconvolved from middle trace with an artificial quantal IPSC. qs ${ }^{-1}$, quanta per second. Inset shows the action potentials and release rate histogram from a portion of the same traces on expanded time scale to demonstrate regions used to calculate synchronous ( $S$ ) and asynchronous (AS) release. Release is calculated from the filled area in the release rate histogram. $\boldsymbol{B}$, Same pair shown in $\boldsymbol{A}$ after KA application. $\boldsymbol{C}$, Total synchronous (gray) and asynchronous (black) release for groups of action potentials and entire train in the presence of $1 \mu \mathrm{m} \mathrm{KA}$ as a percentage of baseline, $n=6$. $\boldsymbol{D}$, Synchronicity ratio (SR, synchronous/asynchronous release) before (black) and after (gray) KA application for consecutive groups of 5 presynaptic action potentials throughout a train and for entire train, $n=6 .{ }^{*} p<0.05$ vs baseline.

Fig. 4B,D; supplemental Fig. S4, available at www.jneurosci. org as supplemental material).

\section{KA specifically inhibits synchronous GABA release}

We have found that application of KA causes a reduction in the peak amplitude of IPSCs produced by CCK interneurons in PCs. This is primarily a measure of synchronous GABA release, however CCK interneurons potentially mediate much of their inhibitory action via asynchronous release (Hefft and Jonas, 2005; Daw et al., 2009). To test whether asynchronous release onto PCs is also inhibited by KA application we delivered 10 trains of 25 presynaptic action potentials at $50 \mathrm{~Hz}$ before and after $10 \mathrm{~min}$ in the presence of $1 \mu \mathrm{M} \mathrm{KA}$. We used deconvolution analysis (see methods) to calculate the amount of GABA released in $20 \mathrm{~ms}$ time windows corresponding to each action potential and throughout the whole train. KA $(1 \mu \mathrm{M})$ caused a reduction in overall synchronous release throughout the train that was greater than that seen for asynchronous release (synchronous release $=67 \pm 21 \%$ baseline, asynchronous release $=91 \pm 27 \%$ baseline, $p<0.05, n=6$, Fig. $5 A, B, D)$. This effect was most apparent during the first 5 action potentials of the train when synchronous release is greatest in control conditions (synchronous release first 5 action potential $=60 \pm 20 \%$ baseline, asynchronous release $=110 \pm 29 \%$ baseline $p<0.05$, Fig. $5 A-C$ ). This resulted in an SR that was lower throughout the train in the presence of $1 \mu \mathrm{M}$ KA (baseline SR $=1.9 \pm 0.4,1 \mu \mathrm{M} \mathrm{KA} \mathrm{SR}=1.4 \pm 0.3, p<0.01, n=6$,
Fig. 5A,B,D), which was again most pronounced early in the train (baseline SR first 5 action potentials $=8.1 \pm 1.8$, $1 \mu \mathrm{M} \mathrm{KA} \mathrm{SR}=4.0 \pm 1.1, p<0.05, n=$ 6, Fig. $5 A, B, D)$. This decrease in synchronicity is a specific effect of KAR activation and not a general feature of reduced release probability as we have previously shown than SR increases when release probability is reduced in low extracellular $\mathrm{Ca}^{2+}$ (Daw et al., 2009).

\section{Discussion}

We have shown that the depressing effect of KAR activation on IPSCs in the hippocampus is dependent on the identity of both the presynaptic and postsynaptic cell type. In PCs IPSCs mediated by CCK interneurons are strongly depressed by KAR activation whereas those mediated by PV interneurons are unaffected. In interneurons IPSCs mediated by either presynaptic cell class are also unaffected. Furthermore we have shown that the depression is restricted to synchronous GABA release. Asynchronous GABA release, a prominent mode of synaptic transmission by CCK interneurons, is unaffected by KA application.

A decrease in IPSC amplitude in response to KAR activation has been shown by a number of groups but these studies focused on IPSCs evoked by extracellular stimulation (Clarke et al., 1997; Rodríguez-Moreno et al., 1997; Frerking et al., 1999; Behr et al., 2002; Fisahn et al., 2002; Maingret et al., 2005). There are two main disadvantages to this form of stimulation. First there are numerous different interneuron classes in the hippocampus (Klausberger and Somogyi, 2008) and extracellular stimulation activates axons from many cell classes at the same time. As a result the source of IPSCs is unknown and it is not possible to identify any cell-type-specific effects. Second, KA directly depolarizes interneurons causing spontaneous firing (Cossart et al., 1998; Fisahn et al., 2002) so that release probability at stimulated synapses will be affected by previous, spontaneous, activity. This phenomenon may also explain the result of one previous study using paired recordings which, unlike our study, did not prevent spontaneous presynaptic firing by injecting hyperpolarizing current (Jiang et al., 2001). As would be expected IPSCs mediated by synapses showing low release probability in baseline conditions, and therefore likely to show frequency-dependent facilitation, were increased in amplitude when KA application caused spontaneous firing. This study also made no attempt to identify the interneuron classes involved.

The ability, in our study, to segregate IPSCs based on presynaptic cell class and to prevent spontaneous firing probably also explains why we were able to see a decrease in IPSC amplitude which was not dependent on the increase in sIPSCs or GABA $_{B}$ receptor activation (Frerking et al., 1999). Thus, we both conclusively demonstrated the inhibitory effect of KAR activation on IPSCs in the 
hippocampus and have shown that this effect is dependent on the identity of both presynaptic and postsynaptic cell type.

In our recordings of interneuron to interneuron synapses we observed no effect of KAR activation whether PV or CCK interneurons were presynaptic. Synapses made by CCK interneurons on to interneurons produce small and highly variable amplitude uIPSCs (Daw et al., 2009) which accounts for the large variability seen in this dataset and as such we cannot entirely rule out that the small, nonsignificant increase, in IPSC amplitude is consistent with a facilitatory effect of KA on interneuron IPSCs (Mulle et al., 2000; Cossart et al., 2001). Alternatively these changes may occur at synapses made by other classes of interneuron which were not studied here.

Very recently another study, which also used paired recordings, reached similar conclusions regarding the identity of interneurons mediating the KA-induced reduction in evoked IPSCs (Lourenço et al., 2010). This study used synaptically released glutamate to activate KARs and elegantly showed that the depressive action of KARs is due to an enhancement of the effect of a CB1 receptor action produced by mGluR-dependent release of endocannabinoids. Contrary to this finding we find that the effect of KAR activation remains in the presence of a CB1 antagonist. This was expected as in our experimental design there is likely no mGluR activation to cause endocannabinoid release. The reason for discrepancy in effects of KAR activation in the absence of endocannabinoids is less obvious. It is possible that exogenously applied agents activate a population of KARs in a membrane domain not accessible to the train protocol used by Lourenço et al. (2010). The ability to adjust presynaptic holding potential in paired recordings makes it unlikely that this apparently presynaptic effect is due to axonal spread of depolarization caused by somatodendritic receptors (Alle and Geiger, 2008). One interesting possibility is raised by the fact that vesicular glutamate transporter 3 (VGlut3) is expressed in the terminals of a subset of CCK-containing interneurons in the hippocampus (Somogyi et al., 2004). Thus it is possible that these presynaptic receptors are physiologically activated by the corelease of glutamate from the interneurons themselves and that such receptors may not be accessible to glutamate released during the train protocol.

Previously presynaptic KARs have been demonstrated both to act metabotropically (Rodríguez-Moreno and Lerma, 1998) or via axonal depolarization (Schmitz et al., 2000; Semyanov and Kullmann, 2001); our results do not discriminate between these possibilities. During periods of high-frequency firing, including patterns of activity similar to those observed in vivo (Klausberger et al., 2005), CCK interneurons mediate a large proportion of their inhibitory effect by asynchronous release of GABA (Hefft and Jonas, 2005; Daw et al., 2009). We have demonstrated that while KAR activation causes a reduction in the peak IPSC amplitude, mediated by synchronous GABA release, the amount and distribution of asynchronous GABA release during long trains is unaffected. This result strengthens the conclusion that the reduction in IPSC amplitude is due to a reduction in presynaptic release, inferred from the increase in failure rate, as any postsynaptic depression would reduce both synchronous and asynchronous IPSCs equally. This includes postsynaptic artifacts caused by the increase in sIPSCs. Currently it is not know precisely what determines whether neurotransmitter is released synchronously or asynchronously and it is difficult to determine why KARs should affect the 2 processes differently. It has been suggested that different synaptotagmin isoforms mediate the two modes of release (Sun et al., 2007) and with a metabotropic mode of KAR action it might be possible to selectively inhibit only the isoform responsible for synchronous release.
In vivo presynaptic KARs are likely to be activated by glutamate released during periods of intense local activity. Such periods are also likely to lead to higher firing frequencies in interneurons including CCK interneurons. High firing frequency will increase asynchronous GABA release while KAR activation will decrease synchronous release. This suggests that CCK interneurons contribute to precisely timed phasic inhibition during basal conditions but are specialized to produce a prolonged dampening of network activity during periods of hyperexcitability. Alternatively if KARs are activated by interneuron-released glutamate this selective reduction in synchronous release could explain why the proportion of synchronous to asynchronous release decreases throughout a train of presynaptic action potentials.

\section{References}

Alle H, Geiger JR (2008) Analog signalling in mammalian cortical axons Curr Opin Neurobiol 18:314-320.

Behr J, Gebhardt C, Heinemann U, Mody I (2002) Kindling enhances kainate receptor-mediated depression of GABAergic inhibition in rat granule cells. Eur J Neurosci 16:861-867.

Brager DH, Luther PW, Erdélyi F, Szabó G, Alger BE (2003) Regulation of exocytosis from single visualized GABAergic boutons in hippocampal slices. J Neurosci 23:10475-10486.

Clarke VR, Ballyk BA, Hoo KH, Mandelzys A, Pellizzari A, Bath CP, Thomas J, Sharpe EF, Davies CH, Ornstein PL, Schoepp DD, Kamboj RK, Collingridge GL, Lodge D, Bleakman D (1997) A hippocampal GluR5 kainate receptor regulating inhibitory synaptic transmission. Nature 389:599-603.

Cossart R, Esclapez M, Hirsch JC, Bernard C, Ben-Ari Y (1998) GluR5 kainate receptor activation in interneurons increases tonic inhibition of pyramidal cells. Nat Neurosci 1:470-478.

Cossart R, Tyzio R, Dinocourt C, Esclapez M, Hirsch JC, Ben-Ari Y, Bernard C (2001) Presynaptic kainate receptors that enhance the release of GABA on CA1 hippocampal interneurons. Neuron 29:497-508.

Daw MI, Tricoire L, Erdelyi F, Szabo G, McBain CJ (2009) Asynchronous transmitter release from cholecystokinin-containing inhibitory interneurons is widespread and target-cell independent. J Neurosci 29: 11112-11122.

Diamond JS, Jahr CE (1995) Asynchronous release of synaptic vesicles determines the time course of the AMPA receptor-mediated EPSC. Neuron 15:1097-1107.

Fisahn A, Yamada M, Duttaroy A, Gan JW, Deng CX, McBain CJ, Wess J (2002) Muscarinic induction of hippocampal gamma oscillations requires coupling of the M1 receptor to two mixed cation currents. Neuron 33:615-624.

Földy C, Lee SY, Szabadics J, Neu A, Soltesz I (2007) Cell type-specific gating of perisomatic inhibition by cholecystokinin. Nat Neurosci 10:11281130 .

Frerking M, Petersen CC, Nicoll RA (1999) Mechanisms underlying kainate receptor-mediated disinhibition in the hippocampus. Proc Natl Acad Sci U S A 96:12917-12922.

Freund TF, Katona I (2007) Perisomatic inhibition. Neuron 56:33-42.

Goldberg EM, Clark BD, Zagha E, Nahmani M, Erisir A, Rudy B (2008) K+ channels at the axon initial segment dampen near-threshold excitability of neocortical fast-spiking GABAergic interneurons. Neuron 58:387-400.

Hefft S, Jonas P (2005) Asynchronous GABA release generates long-lasting inhibition at a hippocampal interneuron-principal neuron synapse. Nat Neurosci 8:1319-1328.

Jiang L, Xu J, Nedergaard M, Kang J (2001) A kainate receptor increases the efficacy of GABAergic synapses. Neuron 30:503-513.

Jonas P, Hefft S (2010) GABA release at terminals of CCK-interneurons: synchrony, asynchrony and modulation by cannabinoid receptors [commentary on Ali and Todorova]. Eur J Neurosci 31:1194-1195.

Karson MA, Tang AH, Milner TA, Alger BE (2009) Synaptic cross talk between perisomatic-targeting interneuron classes expressing cholecystokinin and parvalbumin in hippocampus. J Neurosci 29:4140-4154.

Katona I, Sperlágh B, Sík A, Käfalvi A, Vizi ES, Mackie K, Freund TF (1999) Presynaptically located CB1 cannabinoid receptors regulate GABA release 
from axon terminals of specific hippocampal interneurons. J Neurosci 19:4544-4558.

Kawaguchi Y, Katsumaru H, Kosaka T, Heizmann CW, Hama K (1987) Fast spiking cells in rat hippocampus (CA1 region) contain the calciumbinding protein parvalbumin. Brain Res 416:369-374.

Klausberger T, Somogyi P (2008) Neuronal diversity and temporal dynamics: the unity of hippocampal circuit operations. Science 321:53-57.

Klausberger T, Marton LF, O’Neill J, Huck JH, Dalezios Y, Fuentealba P, Suen WY, Papp E, Kaneko T, Watanabe M, Csicsvari J, Somogyi P (2005) Complementary roles of cholecystokinin- and parvalbumin-expressing GABAergic neurons in hippocampal network oscillations. J Neurosci 25:9782-9793.

Lourenço J, Cannich A, Carta M, Coussen F, Mulle C, Marsicano G (2010) Synaptic activation of kainate receptors gates presynaptic $\mathrm{CB}(1)$ signaling at GABAergic synapses. Nat Neurosci 13:197-204.

Maingret F, Lauri SE, Taira T, Isaac JT (2005) Profound regulation of neonatal CA1 rat hippocampal GABAergic transmission by functionally distinct kainate receptor populations. J Physiol 567:131-142.

Mulle C, Sailer A, Swanson GT, Brana C, O'Gorman S, Bettler B, Heinemann SF (2000) Subunit composition of kainate receptors in hippocampal interneurons. Neuron 28:475-484.

Pinheiro PS, Mulle C (2008) Presynaptic glutamate receptors: physiological functions and mechanisms of action. Nat Rev Neurosci 9:423-436.

Rodríguez-Moreno A, Lerma J (1998) Kainate receptor modulation of GABA release involves a metabotropic function. Neuron 20:1211-1218.

Rodríguez-Moreno A, Herreras O, Lerma J (1997) Kainate receptors presynaptically downregulate GABAergic inhibition in the rat hippocampus. Neuron 19:893-901.
Rodríguez-Moreno A, López-García JC, Lerma J (2000) Two populations of kainate receptors with separate signaling mechanisms in hippocampal interneurons. Proc Natl Acad Sci U S A 97:1293-1298.

Schmitz D, Frerking M, Nicoll RA (2000) Synaptic activation of presynaptic kainate receptors on hippocampal mossy fiber synapses. Neuron 27: 327-338.

Schmitz D, Mellor J, Frerking M, Nicoll RA (2001) Presynaptic kainate receptors at hippocampal mossy fiber synapses. Proc Natl Acad Sci U S A 98:11003-11008.

Semyanov A, Kullmann DM (2001) Kainate receptor-dependent axonal depolarization and action potential initiation in interneurons. Nat Neurosci 4:718-723.

Somogyi J, Baude A, Omori Y, Shimizu H, El Mestikawy S, Fukaya M, Shigemoto R, Watanabe M, Somogyi P (2004) GABAergic basket cells expressing cholecystokinin contain vesicular glutamate transporter type 3 (VGLUT3) in their synaptic terminals in hippocampus and isocortex of the rat. Eur J Neurosci 19:552-569.

Sun J, Pang ZP, Qin D, Fahim AT, Adachi R, Südhof TC (2007) A dual$\mathrm{Ca} 2+$-sensor model for neurotransmitter release in a central synapse. Nature 450:676-682.

Vignes M, Clarke VR, Parry MJ, Bleakman D, Lodge D, Ornstein PL, Collingridge GL (1998) The GluR5 subtype of kainate receptor regulates excitatory synaptic transmission in areas CA1 and CA3 of the rat hippocampus. Neuropharmacology 37:1269-1277.

Wilson RI, Kunos G, Nicoll RA (2001) Presynaptic specificity of endocannabinoid signaling in the hippocampus. Neuron 31:453-462. 